\title{
POLA MAKAN DAN KEJADIAN HIPERTENSI
}

\section{EATING PATTERNS AND EVPERTENSION EVENTS}

\author{
Sunarto Kadir \\ Fakultas Olahraga dan Kesehatan \\ Univeristas Negeri Gorontalo \\ Kontak Penulis: sunarto.kadir@yahoo.co.id
}

\begin{abstract}
ABSTRAK
Memperhatikan pola makan sehari-hari mampu meminimalisir risiko terjadinya penyakit, salah satunya Hipertensi. Penelitian ini dilakukan pada penderita Hipertensi di wilayah kerja Puskesmas Dungaliyo Kabupaten Gorontalo. Tujuan penelitian adalah untuk menganalisis pengaruh pola makan terhadap kejadian Hipertensi. Jenis penelitian yang digunakan adalah analitik kuantitatif dengan pendekatan cross sectional. Populasi adalah seluruh penderita Hipertensi yang tercatat pada tahun 2018 di wilayah kerja Puskesmas Dungaliyo dengan jumlah 192 orang. Sampel diperoleh sebanyak 66 orang yang diambil menggunakan teknik purposive sampling. Data dikumpulkan menggunakan kuesioner dan dianalisis menggunakan uji ChiSquare. Hasil penelitian menunjukkan bahwa 24 responden dengan pola makan buruk, 20 responden mengalami pre-Hipertensi, 13 responden mengalami Hipertensi tingkat satu dan 7 responden mengalami Hipertensi tingkat dua. Terdapat pengaruh pola makan terhadap kejadian Hipertensi di wilayah kerja Puskesmas Dungaliyo Kabupaten Gorontalo. Disarankan masyarakat agar kiranya dapat lebih memperhatikan pola makan yang sehat sehingga bisa meminimalisir risiko Hipertensi.
\end{abstract}

Kata kunci: pola makan; kejadian hipertensi

\begin{abstract}
Paying attention to your daily diet can minimize the risk of disease, one of which is hypertension. This research was conducted on hypertensive patients in the work area of the Dungaliyo District Health Center Gorontalo. The study aimed to analyze the dietary patterns of hypertension. The type of research used is quantitative analytic with cross-sectional research. The population is all hypertensive sufferers added in 2018 in the Dungaliyo Community Health Center working area with 192 people. The samples taken were 66 people taken using purposive sampling technique. Data were collected using a questionnaire and analyzed using the ChiSquare test. The results showed that 24 respondents with poor diet, 20 respondents increased pre-hypertension, 13 respondents increased hypertension one and 7 respondents increased second-degree hypertension. Regarding diet for the incidence of hypertension in the Dungaliyo District Health Center work area, Gorontalo. The community considers a healthy diet to minimize the risk of hypertension.
\end{abstract}

Keywords: diet; hypertension incidence 


\section{PENDAHULUAN}

Pola makan merupakan perilaku paling penting yang dapat mempengaruhi keadaan gizi. Hal ini disebabkan karena kuantitas dan kualitas makanan dan minuman yang dikonsumsi akan mempengaruhi asupan gizi sehingga akan mempengaruhi kesehatan individu dan masyarakat. Gizi yang optimal sangat penting untuk pertumbuhan normal serta perkembangan fisik dan kecerdasan bayi, anak-anak, serta seluruh kelompok umur. (Permenkes RI No.14, 2014).

Gaya hidup modern yang saat ini dianut oleh manusia cenderung membuat manusia menyukai hal-hal yang instan. Akibatnya, mereka cenderung malas beraktivitas fisik dan gemar mengonsumsi makanan yang instan, yang memiliki kandungan natrium yang tinggi (Ratnawati \& Aswad, 2019). Menerapkan pola makan yang sehat memang tidak dapat menjamin jika akan terbebas dari penyakit, namun setidaknya memperhatikan asupan pola konsumsi makanan seharihari mampu meminimalisir risiko kemungkinan seseorang terserang penyakit.

Penatalaksanaan Hipertensi dapat dilakukan dengan dua cara yakni cara farmakologi menggunakan obat-obatan dan non farmakologi yakni dengan modifikasi gaya hidup termasuk asupan makanan (Buheli \& Usman, 2019). Hipertensi merupakan salah satu penyakit yang mengakibatkan kesakitan yang tinggi. Hipertensi atau penyakit darah tinggi adalah gangguan pada pembuluh darah yang mengakibatkan suplai oksigen dan nutrisi yang dibawa oleh darah terhambat sampai ke jaringan tubuh yang membutuhkannya.

Penyakit Hipertensi telah membunuh 9,4 juta warga di dunia setiap tahunnya. Menurut data Dinas Kesehatan Provinsi Gorontalo tahun 2017 terdapat 12.387 kasus lama, 7994 kasus baru dan 353 kematian akibat Hipertensi. Khusus untuk Kabupaten Gorontalo menurut data Dinas Kesehatan Kabupaten Gorontalo bulan Desember 2017 terdapat 1514 kasus Hipertensi.

Puskesmas Dungaliyo yang berada di Kecamatan Dungaliyo Kabupaten Gorontalo adalah salah satu pusat pelayanan kesehatan yang melayani masyarakat dengan beragam usia dan permasalahan kesehatannya. Jumlah kasus Hipertensi di Puskesmas Dungaliyo menurut data awal tahun 2017 ada 1077 yang menderita Hipertensi dari yang umur 20-60 tahun baik perempuan maupun laki-laki.

Berdasarkan data yang ditemukan bahwa bulan Januari 2017 terdapat 63 penderita Hipertensi, bulan Februari terdapat 98 penderita Hipertensi, bulan Maret 121 penderita Hipertensi, bulan April 81 penderita Hipertensi, bulan Mei 44 penderita Hipertensi, bulan Juni 33 penderita Hipertensi, bulan Juli 111 penderita Hipertensi, bulan Agustus 95 penderita Hipertensi, bulan September 33 penderita Hipertensi, bulan Oktober 152 penderita Hipertensi, bulan September 100 penderita Hipertensi dan pada bulan Desember ada 146 penderita Hipertensi.

Dari data tersebut jumlah laki-laki yang menderita Hipertensi sebanyak 387 (35,9 \%) dari penderita, sedangkan perempuan ada 620 penderita Hipertensi (57,5\%). Sementara itu, pada tahun 2018, menurut data pada bulan Maret dan April jumlah penderita baru Hipertensi tercatat sebanyak 192 orang.

Penelitian ini bertujuan untuk menganalisis pengaruh pola makan terhadap kejadian Hipertensi di wilayah kerja Puskesmas Dungaliyo Kabupaten Gorontalo. Masyarakat di wilayah kerja Puskesmas Dungaliyo Kabupaten Gorontalo sebaiknya mulai menerapkan pola hidup sehat, termasuk memperhatikan asupan makanan yang dikonsumsi dan mulai beralih ke makanan yang sehat semisal sayur dan buah-buahan yang baik untuk kesehatan tubuh. Banyak mengkonsumsi air juga disarankan untuk menjaga kesehatan tubuh karena air akan dapat melancarkan peredaran darah sehingga oksigen yang mengalir ke otak tidak akan terhambat. 


\section{METODE PENELITIAN}

Penelitian ini dilaksanakan di wilayah kerja Puskesmas Dungaliyo Kabupaten Gorontalo, mulai dari tanggal 22 November sampai 12 Desember 2018. Jenis penelitian yang digunakan adalah analitik kuantitatif dengan pendekatan cross sectional. Populasi dalam penelitian ini adalah seluruh penderita Hipertensi yang tercatat pada tahun 2018 di wilayah kerja Puskesmas Dungaliyo Kabupaten Gorontalo yang berjumlah 192 orang. Sampel penelitian diperoleh sebanyak 66 orang menggunakan teknik purposive sampling, yaitu pengambilan sampel berdasarkan pertimbangan peneliti itu sendiri (Sugiyono, 2015). Data yang diperoleh kemudian dianalisis menggunakan uji Chi-Square dengan bantuan program SPSS versi 21.

\section{HASIL PENELITIAN}

1. Pola Makan Responden

Gambar 1. Pola Makan Responden

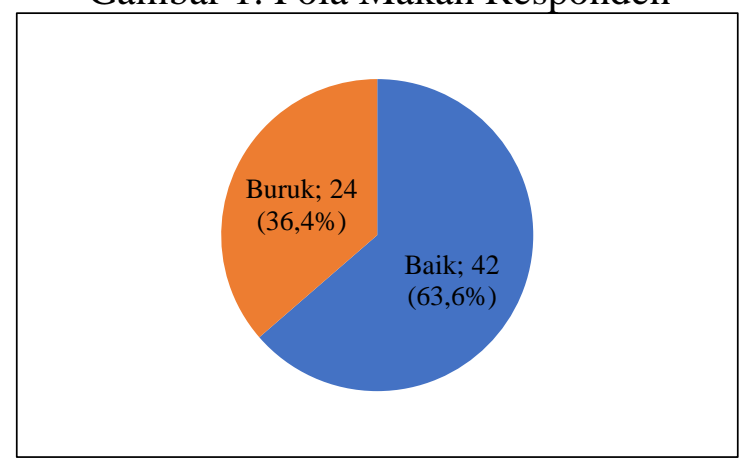

Berdasarkan Gambar 3.1 bahwa responden dengan pola makan baik sebanyak 42 orang $(63,6 \%)$ dan pola makan buruk sebanyak 24 orang $(36,4 \%)$. Pengukuran pola konsumsi makan dilihat dari frekuensi konsumsi makanan yang mengandung lemak setiap harinya.

2. Kejadian Hipertensi

Gambar 2. Kejadian Hipertensi

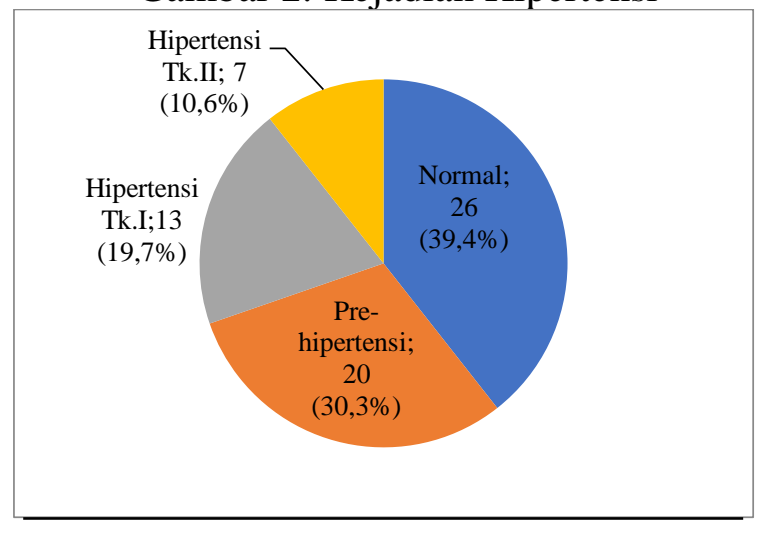

Berdasarkan Gambar 3.2 bahwa responden yang tidak mengalami Hipertensi (normal) sebanyak 26 orang $(39,4 \%)$, pre-hipetensi sebanyak 20 orang $(30,3 \%)$, Hipertensi tingkat I sebanyak 13 orang $(19,7 \%)$ dan Hipertensi tingkat II sebanyak 7 orang $(10,6 \%)$. 
3. Pengaruh Pola Makan terhadap Kejadian Hipertensi

Tabel 1. Tabulasi Silang Variabel Pola Makan dengan Kejadian Hipertensi di Wilayah Kerja Puskesmas Dungaliyo Kabupaten Gorontalo

\begin{tabular}{|c|c|c|c|c|c|c|c|c|c|c|c|}
\hline \multirow{3}{*}{$\begin{array}{c}\text { Pola } \\
\text { Makan }\end{array}$} & \multicolumn{8}{|c|}{ Kejadian Hipertensi } & \multirow{2}{*}{\multicolumn{2}{|c|}{ Total }} & \multirow{3}{*}{$p$-value } \\
\hline & \multicolumn{2}{|c|}{ Normal } & \multicolumn{2}{|c|}{ Pre-Hipertensi } & \multicolumn{2}{|c|}{ Hipertensi Tk.I } & \multicolumn{2}{|c|}{ Hipertensi Tk.II } & & & \\
\hline & $\mathrm{n}$ & $\%$ & $\mathrm{n}$ & $\%$ & $\mathrm{n}$ & $\%$ & $\mathrm{n}$ & $\%$ & $\mathrm{n}$ & $\%$ & \\
\hline Baik & 24 & 36,4 & 12 & 18,2 & 4 & 6,1 & 2 & 3,0 & 42 & 63,6 & \\
\hline Buruk & 2 & 3,0 & 8 & 12,1 & 9 & 13,6 & 5 & 7,6 & 24 & 36,4 & 0,000 \\
\hline Jumlah & 26 & 39,4 & 20 & 30,3 & 13 & 19,7 & 7 & 10,6 & 66 & 100 & \\
\hline
\end{tabular}

Sumber: Data primer (2018)

Berdasarkan Tabel 3.1 bahwa dari 66 orang sampel, responden dengan pola makan baik sebanyak 42 orang $(63,6 \%)$, dari jumlah tersebut responden yang tidak mengalami Hipertensi sebanyak 24 orang $(36,4 \%)$, pre-Hipertensi sebanyak 12 orang $(18,2 \%)$, Hipertensi tingkat I sebanyak 4 orang $(6,1 \%)$ dan Hipertensi tingkat II sebanyak 2 orang $(3,0 \%)$. Sedangkan 24 orang $(36,4 \%)$ responden dengan pola makan buruk, dari jumlah tersebut yang tidak mengalami Hipertensi sebanyak 2 orang $(3,0 \%)$, pre-Hipertensi sebanyak 8 orang $(12,1 \%)$, Hipertensi tingkat I sebanyak 9 orang $(13,6 \%)$ dan Hipertensi tingkat II sebanyak 5 orang $(7,6 \%)$. Dari hasil uji ChiSquare didapatkan nilai $\mathrm{p}=0,000(\mathrm{p}<0,05)$, artinya terdapat pengaruh pola makan terhadap kejadian Hipertensi di wilayah kerja Puskesmas Dungaliyo Kabupaten Gorontalo.

\section{PEMBAHASAN}

Pada masyarakat di wilayah kerja Dungaliyo Kecamatan Dungaliyo Kabupaten Gorontalo yang menjadi sampel penelitian terdapat 24 orang dengan pola konsumsi makan yang buruk, dan hampir seluruhnya yaitu sebanyak 22 orang mengalami Hipertensi baik dari tingkatan preHipertensi sampai dengan Hipertensi tingkat II. Hal tersebut cukup membuktikan bahwa dengan pola makan utamanya makanan berlemak yang $\geq 3$ kali dalam sehari dapat menyebabkan Hipertensi. Makanan yang berlemak didapatkan dari konsumsi daging, makanan yang bersantan dan makanan cepat saji (goreng-gorengan).

Sebaran dari data pola makan dengan kejadian Hipertensi tidaklah merata, ada beberapa bahan makanan pencegah yang sering dikonsumsi penderita Hipertensi ada dalam kategori Hipertensi stadium I dan II. Hal ini dikarenakan banyak sekali faktor yang berkaitan dengan kejadian Hipertensi, tidak hanya asupan makanan. Kepatuhan dalam minum obat dan cara mengkonsumsi bahan makanan juga berkaitan dengan efektivitas bahan makanan yang dikonsumsi sebagai pencegah Hipertensi Secara teori, lemak memang diperlukan oleh tubuh sebagai zat pelindung dan pembangun. Tetapi, apabila konsumsinya berlebihan akan meningkatkan terjadinya plak dalam pembuluh darah, yang lebih lanjut akan menimbulkan terjadinya Hipertensi (Windyasari, 2016). Ramayulis (2010) mengatakan pola makan yang salah dapat menyebabkan peningkatan tekanan darah seperti kebiasaan mengkonsumsi makanan berlemak terutama pada asupan lemak jenuh dan kolesterol.

Pada penelitian ini terdapat terdapat 13 orang penderita Hipertensi tingkat I dan 7 orang penderita Hipertensi tingkat II walaupun memiliki pola konsumsi makan yang baik. Menurut peneliti hal tersebut disebabkan adanya faktor pencetus lain terjadinya penyakit Hipertensi. Faktor tersebut adalah faktor usia yang dapat mempengaruhi terjadinya Hipertensi, dimana pada usia lansia, kemampuan tubuh mengalami kemunduran fungsi, serta rentan mengalami penyakit. 
Hasil penelitian ini sejalan dan memperkuat penelitian sebelumnya seperti oleh Siti (2012) menyimpulkan adanya hubungan yang bermakna antara tingkat konsumsi lemak dengan kejadian Hipertensi pada lansia di UPT Pelayanan Sosial Jember. Demikian pula penelitian oleh Windyasari (2016) yang mendapatkan hasil bahwa tingkat konsumsi makanan yang berhubungan signifikan dengan kejadian Hipertensi pda pra lansia di wilayah kerja UPTD Puskesmas Kampung Bangka Kecamatan Pontianak yang mencakup dua variabel yaitu lemak $(\mathrm{p}=0,015)$ dan natrium $(\mathrm{p}=$ 0,049).

\section{KESIMPULAN}

Sebagian besar dari dari responden di wilayah kerja Puskesmas Dungaliyo memiliki pola makan baik. Akantetapi mesti berhati-hati lagi agar tidak terkena penyakit Hipertensi, hal ini dikarenakan masih banyak faktor yang bisa mempengaruhi terjangkitnya penyakit yang berbahaya ini misalnya merokok, begadang ataupun hal lain yang terkait dengan pola hidup.

\section{REFERENSI}

Buheli, K. L., \& Usman, L. (2019). Faktor Determinan Kepatuhan Diet Penderita Hipertensi. Jambura Health and Sport Journal, 1(1), 20-24. Retrieved from http://ejurnal.ung.ac.id/index.php/jhsj/article/view/2049

Permenkes RI No.14 Tahun 2014 tentang Pedoman Gizi Seimbang.

Ramayulis. 2010. Menu dan Resep untuk Penderita Hipertensi, Penebar Plus+: Jakarta.

Ratnawati, \& Aswad, A. (2019). Efektivitas Terapi Pijat Refleksi dan Terapi Benson terhadap Penurunan Tekanan Darah pada Penderita Hipertensi. Jambura Health and Sport Journal, 1(1), 40-47. Retrieved from http://ejurnal.ung.ac.id/index.php/jhsj/article/view/2052

Siti. (2012). Hubungan antara Tingkat Konsumsi Makanan dengan Kejadian Hipertensi pada Lansia (Studi di UPT Palayanan Sosial Lanjut Usia Jember). Skripsi. Universitas Jember, Jember.

Windyasari. (2016). Hubungan Antara Konsumsi Makanan dengan Kejadian Hipertensi pada Pra Lansia di Wilayah Kerja UPTD Puskesmas Kampung Bangka Kecamatan Pontianak Tenggara. Naskah Publikasi. Universitas Tanjungpura, Pontianak 